\title{
The Study on Decision Mechanism of Information Systems Outsourcing in Taiwan Financial Services Industry
}

\author{
Tzu-Chun Sheng ${ }^{1}$, Meng-Yin Shi ${ }^{1} \&$ Jun-Hao $\mathrm{Li}^{1}$ \\ ${ }^{1}$ Department of Finance, Ling Tung University, Taiwan, R.O.C. \\ Correspondence: Tzu-Chun Sheng, Department of Finance, Ling Tung University, Taichung City, Taiwan, R.O.C. Tel: \\ 886-989-997-776. E-mail: morgan1125@teamail.ltu.edu.tw
}

Received: October 22, 2014

Accepted: November 6, 2014

Online Published: November 16, 2014

doi:10.5430/afr.v3n4p151

URL: http://dx.doi.org/10.5430/afr.v3n4p151

\begin{abstract}
The intense market competition provided higher demands on the financial institution with across-the-aboard opening for financial services industry in Taiwan. Hence, the financial services industry in Taiwan as the research object aims at exploring the decision mechanism and influential factors while establishing the operational decision of information systems outsourcing. Firstly, the study compiled the related literatures regarding influential operational factors on Information Systems Outsourcing by Financial Services Industry. The modified Delphi approach demarcated Outsourcing Theory into five evaluation criteria, such as "The Enterprise Organization and Management", "Costs and Financial Factors", "System Structure Technology", "The Enterprise Ethic and Laws", and "Outsourcing Contractor Factors" and seventeen sub-criteria. Fuzzy Analytic Hierarchy Process clarified the operational decision mechanism of information system outsourcing committed by Financial Services Industry through setting up the structure of Analytic Hierarchy Process and expert questionnaires. The empirical results of this study enable to not only make up for the insufficient former related literatures but also be proposed for the reference of operational decision of information system outsourcing established by Financial Services Industry in either Taiwan or other Asian countries.
\end{abstract}

Keywords: Fuzzy analytic hierarchy process, Information systems outsourcing, Modified Delphi approach, Taiwan financial services industry

\section{Introduction}

Based on the Directorate General of Budget, Accounting and Statistics, Executive Yuan, Taiwan (2011), the expenditure of overall information funds is US\$7.4 billion, 1.6\% of GDP in Taiwan. The rate of information funds between the financial services industry and insurance industry is $23.30 \%$ of overall expenditure, which is the top rank among all industries in Taiwan. Not only has the operational mode of information system outsourcing been the tendency in Asia Pacific Zone, but the grand total is expected to increase constantly in Taiwanese market. All financial services industry in Taiwan has been encountering more and more intense globalization market competition since taking parting in the World Trade Organization (WTO). As the result, either partial or all information system is committed to specialized outer contractors to assist in formulating and managing by more and more enterprises.

Compared with other industries, information system outsourcing of financial services industry is the most widely discussed. The financial services industry is based on the financial-oriented industry, associated with other financial services industry of non-bank financial industry. The provider of financial services offers all financing, loan and other financial services. Therefore, the information system of financial business not only introduces the innovative thoughts and technology, but also increases business competition in the financial services industry. Based on all factors, the information system outsourcing is committed to outer contractors to operate and manage by financial services industry. The operation of information system outsourcing enables the enterprise to offer the financial business with timeliness and mobility to customers. Tarricone (1997) claimed the managers of financial services industry are supposed to be aware of business objects and the aim of information systems outsourcing operation. Consequently, the information system outsourcing operation is concerned with the utilization and plan of organizational strategy, adequate contract contents, the option of outsourcing services suppliers and the mutual nexus between the enterprise and services supplier. 
The new concept of information system outsourcing operation has initiated for a while. In the early stage of $80 \mathrm{~s}$, the renowned enterprise, Kodak, in the US entrusted its information management to some specialized information companies, such as IBM, DEC, Business-Land and so on, which rang up the curtain on information system outsourcing operation in global enterprise. The definition of information system outsourcing operation was defined as partial equivalent outlook and opinion between former literatures and studies. According to Meyer (1994) and Saunders, Gebelt and Hu (1997), so-called information system outsourcing operation was committed and paid by another company to deal with the establishment and management of information system. The enterprise concluded the informational events within the specific range and shifted to outer information services dealer subsequent to considering the inner sources and operational strategies of organization. Due (1992) and Palvia (1995) reported either partial or all information process, hardware, software, communications network and system operation were entrusted to outer information services dealer by enterprise. The partial or all information technology with related services was shifted to outer suppliers by contract or selling from the enterprise. The suppliers offered information technology management and services strategy under specific time and costs control. As a result, the modes of information system outsourcing operation is able to separate into three parts, the enterprise put up all contribution of funds, partial contribution of funds, contractor put up the funds by itself or entrusted to outer management (Laabs, 1993; Willcocks, Lacity, \& Fitzgerald, 1995). The enterprise entrusted the information system outsourcing to the outer dealer, including the development and maintenance of applied software, the operation of information center, the research of information science and technology, the management of communications network, database management, the disease recovery of supporting and applied maintenance training of information science and maintenance (Gordon, 1994; Nam, Rajagopalan, Rao, \& Chaudhury, 1996; Lee \& Kim, 1999; Lee, Huynh, Kwok, \& $\mathrm{Pi}, 2003)$.

The obvious fact, integrated with former literatures and studies, is information system outsourcing operation realized the spirit of "specialized task is handed over to specialized manager". The information applied system which resulted in the difficulty of carrying out the task and the addition of costs is rather complicated. The management of specialized outer information contractors will enable the enterprise operation to be more flexible so that the inner personnel of enterprise are able to concentrate on the development of core business. Accordingly, the inner information not only is operated fully and increases the opportunities of learning for employees. Inevitably, the process of each project management might encounter a deal of uncertainty as well as the task at each stage might deviate from original plan (Brown, Malveau, Brown, McCormick, \& Mowbray, 1998). Consequently, the advantages and disadvantages of information system outsourcing operation strategies are adapted discussed by some of the literatures and studies.

With regard to the advantages of information system outsourcing operation strategy, Lacity, Willcocks and Feeny (1995) considered the information system outsourcing operation will be committed to enhance the technology, improve the strategy, intensify operational flexibility, reduce the costs, consolidate management capability and the employees are able to concentrated on core business. Besides, the systems maintenance, expansion and the performance of technology update in information management department will be promoted. According to Antonucci and Tucker (1998), the specialized competence of enterprise is supposed to achieve the goal expeditiously, distract the risk and ease the burden of secondary task of inner personnel. Relatively, most of manpower will be engaged in the accomplishment of main operational task of the enterprise, which assists the enterprise manager to reduce unnecessary employment organization and waste. As a result, the inner resource of enterprise will be drawn upon fully. With relation to the finance, Klepper and Jones (1999) claimed the enterprise should economize expenses as possible as it can, establish definite budget standard, downsize the excess personnel of information department and concentrate on main business competition. Business mode of information system outsourcing operation facilitated the mutual benefits between the enterprise and committed contractor.

As far as the enterprise is concerned, the factors of information system outsourcing operation are separated into insufficient manpower, shortage of science and technology of information or experience and cost consideration. Nevertheless, the strategy of information system outsourcing operation is not zero defect and riskless. Hubbard (1993) described the enterprise must take adaptability of employee, the organization culture, long-term contract management, potential costs, protection of confidential information, quality control and management of outsourcing operation into consideration while deciding to adopt the information system outsourcing operation . In the process of carrying out the information system outsourcing, at meanwhile, the enterprise encountered all risks frequently while taking advantage of limited resource and time. Providing the enterprise disabled to identify the risk and management risk effectively, the failure would be resulted in by adoption of the information system outsourcing operation. Klepper and Jones (1999) also found fail quality management and operation management procedure resulted in the 
disclosure of inner information of enterprise. Therefore, the infringement of confidentiality and intellectual property rights of enterprise also causes the damage easily. Moreover, according to Lacity and Hirschheim (1995), the original keystone of work would be shifted to task execution related information strategy after the enterprise entrusted its task to information system outsourcing operation. The science and technology of information is incomplete core competence of enterprise operation, but a dispensable tool to enhance competition. The enterprise may lose future domination of competence development.

Undeniably, deciding a commission of information system outsourcing operation is extremely difficult for all enterprise with all-inclusive financial services. Meanwhile, the enterprise needs to encounter follow-up questions beyond answering. Would the expenditures and cost be increased subsequence to adopting the information system outsourcing operation? How to figure out the technical problems of information services platform and provide the enterprise flexible information management resources? How to choose capable and reliable partners and provide complete and secure information management services? Would the committed contractor provide new system conformed to the business requirement and future new products or services? The issues herein must be taken into account by the banks or other financial services enterprise. Accordingly, the purpose of study is analyzing the banks and other financial services enterprises whether considering the influential factors of inner or outer of the enterprise in the process of adopting information system outsourcing strategy. These factors will impact the establishment and execution of strategy. The empirical result is able to support the insufficient former related literatures and be proposed for the reference of decision of information system outsourcing established by financial services industry.

\section{Literature Review}

This chapter aims at summarizing, exploring retrospectively and accounting for related theoretical literatures of the main issue on this study. The enterprise is suppose to take inner and outer influential factors into consideration while carrying out the decision of adopting the mode of information system outsourcing operation, which is the focal point on literature reviews.

\subsection{Inner Factors with regard to the Establishment of Information System Outsourcing Operation Decision in Financial Services Industry}

Generally speaking, the factors influenced the development of financial services industry are able to separate inner factors and outer factors. These factors result in organizational risk or operating risk probably. Inner factors refer to the inner risk caused by the personnel problems or unequal resources allocation, such as the interference of decision, employee opposition and so on. Outer factors refer to the uncontrollable outer risks, such as the changes of outer environment and system malfunction...etc. Antonucci and Tucker (1998) described the exceptional specialized competent is drawn upon to distract the risk by financial institution; additionally, mitigating the burden of secondary task of inner personnel enables more manpower to be engaged in main task. The financial institution may be involved in inner and outer risks when the technology changed, the project management failed and the system functions do not meet the requirements. Hence, the environmental factor needs to be taken into consideration while the enterprise is measuring the risk. According to Wallace, Keil and Rai (2004), in project, the organizational environmental risk is regarded as the crucial risk structure, taking the environmental policy, the stability of integral environment and the support of project as an example, which will influence the final performance on integral project. The information system outsourcing operation requires maintaining long-term cooperation between the enterprise and contractors since the procedure is not only complicated, but risk. As the result, the financial institution is unable to take the surface profitability obtained from information system outsourcing operation, but ignore the possible hidden anxiety.

The enterprise is supposed to enhance the management efficiency to shoot for the optimum of resources and allocate the human resource effectively reported by contemporary economic theory. Inadequate human resource allocation may not only reduce the resource efficiency, but increase unnecessary operating costs. Regarding to the human resource, Brown et al. (1998) described one of four major reasons of adoption of information system outsourcing operation is the manpower shortage. Consequently, it is suggested for enterprise to set up the human resource structure so that the skilled people are in their element. In addition, human resource platform is supposed to set up to built the channel between communication and information gathering in financial institutions. Adopting outer contractors enables the infrastructure of information science and technology or human resources in the organization to make major contribution, reported by Loh and Venkatraman (1992). As a result, a greater number of managers in the financial institution take the power of technology to adopt IT-based human resources management. Human resources management, the competent of enhancing organization and object attainment of implementing the strategies have been used to strengthen the human resources management by human resources development. 
Claver, González, Gascó and Llopis (2002) claimed the information system outsourcing operation is another option as the enterprise would like to exploit information operation systems by itself. The information system outsourcing operation enables the enterprise to economize the costs of manpower and technology, increase the flexibility of information department, concentrate on the information core competent and enhance information operation quality. Successful information system outsourcing operation is able to bring about benefits in all its aspects, the key factor of influencing the enterprise provided by Claver et al. (2002). Lacity and Hirschheim (1995) described what the enterprise needs is to focus on long-term investment on basic business, improve the participation and control for the enterprise to the use of software and plunge more time and resources in the work points of enterprise. The enterprise is supposed to enhance managerial management on information systems, enabling the inner resources is adopted effectively as the users' demands change and uncertain investment of research and development. Accordingly, the strategy and mode for the enterprise business is committed the non-core business, enabling the main resources to focus on the development of core competition. The comprehensive decision and further developed plan are adopted by the enterprise for operation.

Besides, the level of support for a decision maker will extremely influence time consuming on controversial issues of project of the operation of information systems outsourcing. Loh (1994) stated that providing lacking of the involvement of senior management, it would result in the difficulties occurring on striving for manpower and resources by the managers in information department in the process of tackling financial information systems; relatively, the facilities, such as the information resources and the efficiency of tackling information system would be influenced as well. Consequently, the major role of decision manager is communicating and coordinating to make the entire process more successfully on the project. Whether a good consultation mechanism is able to be provided is an either successful or failure crucial factor in information system development. Klepper and Jones (1999) concluded the key point of successful information system outsourcing operation is with the support, participation, instruction, supervision and responsible for the outsourcing result in senior management.

As far as the enterprise financial management concerned, the success of the operation of information systems outsourcing will influence the costs on enterprise operation and expenses directly. According to Mortimer, Waterhouse and Court (1993), the reason of adopting information systems operation is to reduce the cost. By means of adopting the operation of "Information Systems Outsourcing", the globalized financial institutions obtained the enhancement of competition and reduced the cost. As the result, the cost economized to increase the system function tied in the continuous of business. Meyer (1994) proclaimed the operation of information systems outsourcing acted as the services industry and disbursed the remuneration to other contractors in order to fulfill all or partial function of information systems. The operation of information systems outsourcing enables the enterprise capital expenditures to turn into the expenses, which made the contractors be responsible for the management of cost and control for the sake of lowering the operational cost on informational system. Klepper and Jones (1999) stated as the variable cost is shifted into by the fixed cost to deduct the cost expenses through assets transferring. Currently, the cognition of operation of information systems outsourcing for financial services industry mostly focused on reducing the cost. In fact, the enterprise is supposed to take the angle of specialized division to asses the over efficiency on operation of information systems outsourcing. Accordingly, the financial services industry is supposed to promptly expand information platform to reduce the information cost and enhance the productivity, which enables the enterprise to gain better return on investment.

The operation of information system outsourcing may result in higher expenses in that the contractors ignored uncertain reality or unpredictable variation. For example, as the management of information systems software is committed to contractors, the enterprise is still charged for the license, upgrade and continuous use of software. Takac (1994) stated the contractor transferring the operation of information systems outsourcing needs to increase the cost on communication and coordination. The cost occurred beyond the budget at all times violated the original object of reducing the cost when the enterprise communicated and coordinated with contractors. In the other hand, to the operation of information systems outsourcing is irreversible chemical reaction. In addition, the enterprise is responsible for the operating failure in that spending more resources to restructure inner information operating systems (Takac, 1994).

The cost expenses on the operation of information systems outsourcing and enterprise financial budget plan are inseparable from each other. The budget and financial plan refer to the series of management activities such as the developed financial budgeting, report, execution, adjustment and control in the enterprise. The enterprise is supposed to tackle with the annual report and financial statement plan and predict the future growth and funds requirements to assure of the reality of annual operating target. According to Lacity and Hirschheim (1995), the types of the operation of information systems outsourcing are able to be separated from the budget ratios of overall information 
management occupied by the amount of operation of outsourcing. Based on the percentage of information department budget taken up by the amount of operation of outsourcing, the overall outsourcing is beyond $80 \%$, the selective outsourcing is beyond $20 \%$ but not to $80 \%$ of the amount of operation of outsourcing, and the least outsourcing is $20 \%$ below. One of the crucial objects is to retrench the cost affected by financial crisis. The enterprise expects to use the lower budget to gain the service with equivalent quality owing to the new demand of operation of information systems outsourcing. Providing the outsourcing contractor is able to strengthen control and management of inner cost to provide the service of operation of information systems outsourcing with low cost and high quality, then being bound to be favored by the financial industry.

The enterprise is able to win the market competitive advantage more easily by means of effective business mode, operating strategies and so on in the process of the growth of enterprise performance. To fit in with the rapid growth and proceeding of business, financial industry acquired information science and technology from establishing the new information systems to win the market advantages while promoting new business or increasing new channel. According to Clemons and Weber (1990), the information systems need to be upgraded by the growth of enterprise performance. However, as the changes of market demands or the variations of environment occurred would result in the risk that the original plan is not qualified with real demand. Aside from the growth of inner demand, the enterprise needed to take the growth of outer market into consideration. For the sake of enhancing competition, by researching and developing the specific technology and operating the specific channel, the enterprise is able to merge to rapidly achieve the growth from outer performance. The enterprise is supposed to keep an eye on balance and coordination, in meanwhile, perfecting inner structure of company.

The enterprise needs to take notice of the risk of information security, which caused the reasons of concordat cost increased constantly by outsourcing contractor. Jennex and Adelakun (2003) stated that the technical competence, the knowledge of outsourcing services receiver, bilateral trust relationship, the basic framework of network communication, information security malfunction risk and intellectual property theft risk...etc of outsourcing contractor are related to the systems and network security. According to Bhattacharyaa, Beharab and Gundersenc (2003), the enterprise would forfeit the comprehension on the core competence if the related business activities with core competence are committed to outer contractor to operate. In that the outsourcing contractor keeps a large chunk of new knowledge without transferring to the enterprise, causing the enterprise to forfeit the knowledge sensitivity of information science and technology, even being unable to win the latest information science and technology. Nevertheless, according to the emphasis of Willcocks et al. (1995), the enterprise would strengthen to invest in the advanced core technical competence rather than disburse the expenses on basic maintenance, such as the software developed cost, network integration and so on. The operation of information systems outsourcing in financial industry has been expended to the management and operation, hardware support, software maintenance and so on in information center. As soon as the contractor possesses the industry knowledge, awareness of outsourcing object and technical competence, the enterprise is committed the information systems to the contractor to assist the decision maker to choose proper project and reduce the risk with decision error. In addition, to avoid the risk, such as the downturn of service quality, interim determination contract or halting the operation, the enterprise is bound to have a contingency plan and arrangement once the malfunction of information systems by outsourcing contractor. As the result, the enterprise is bound to monitor the operating situation of systems and hardware and discover the abnormal operating system in a timely manner.

\subsection{The Effective Factors of Outsourcing Contractor}

How to choose a qualified outsourcing contractor with service quality is one of the crucial factors as the enterprise is establishing the decision, for the reason that the service quality and specialized competence of contract may cause huge influence on the operation in the enterprise. As for the option of proper information systems outsourcing contractor, Grover, Cheon and Teng (1996) claimed the operation of information systems outsourcing enables the enterprise to concentrate the power on core business, strengthen the numbers of skilled personnel, enhance the manpower and the economic scale of technology resources and reduce the risk of technology lag. Meanwhile, the contractor of information systems outsourcing is supposed to assist the enterprise to enhance the control and management competence of information costs, the acquisition of key information skills, the competence of information science and technology. The systems requirement of enterprise is supposed to be defined by the enterprise as well as ask for the Request for Proposal (RFP) suggested by Goldsmith (1994). The manager use the mode of weighting grading to compare contractor's Request for Proposal, cost calculation, the analysis of benefit and effectiveness and the price from the qualified contractor to requiring replying RFP. The contractor with the optimum RFP is able to gain the contract finally. According to Lee and Kim (1999), good partnership is a crucial factor to result in the success to the operation of information systems outsourcing. The contractor is supposed to not only 
possess rather knowledge to the enterprise in its industry, but also fulfill the contractor itself constantly at all times. Only by doing so can the contractor be aware of the demand of the enterprise.

The enterprise has to avoid over-rely on outer contractor while establishing the decision of operation of information systems outsourcing. The system of enterprise itself may be destroyed subsequent to the habit of dependence. The operation of enterprise may be influenced extremely by outer contractor rather than meet the original aspiration of handing the operation of information systems outsourcing over the outer contractor. According to Lacity and Hirschheim (1995) and $\mathrm{Hsu}, \mathrm{Wu}$ and Hsu (2005), the dependence of enterprise to information science and technology has been increased due to the rapid development of information science and technology. With the transition of outer environment, information systems have been shaken off gradually the secondary role of supporting the other managerial activity. The sound outsourcing system has been the imperative weapon to obtain the competitive advantages. Bourantas (1989) stated the enterprise is not supposed to be limited by inner resources and competence providing either strengthening or maintaining the competitive advantages. The enterprise is supposed to adapt the mode of specialized division and gather resources up to the enterprise itself technology of core competition. Faced the risk resulted from over-dependence to outer contractor, the enterprise is supposed to be committed non-competition or the produced activities with poor resources performance to outer contractor to capture outer resources to supplement the disadvantages of the enterprise itself.

While choosing outsourcing contractor, the financial services industry is supposed to take notice of the competence of project management of outsourcing contractor. In accordance with Kimberly and Evanisko (1981), Damanpour and Evan (1984) and Chang and Lee (2007), the project management refers to a couple of crucial elements, such as the proposal, plan, execution, control and management, case closure and so on. The items are able to effectively command the significant management activities, such as the task domination, time, budget, resource, quality, risk, team, communication...etc, which enables the enterprise to produce the optimum performance. According to Lloréns Montes, Ruiz Moreno and Garcia Morales (2005), the competence of organizing project management is a strategy, which is able to strengthen the value as well as the competition to the organization. Robbins and Judge (2006) claimed the enterprise has to consider how to improve the competence of project management to the organization existing under the era of knowledge-based economy. The financial industry is the main stream in services industry in Taiwan, the characters of which are toward not only the integration of financial industry and services industry, but also varieties of financial services. The manager of financial services industry is able to gain the operation and services competence of industry by means of science and technology innovation and application. Daniel and Storey (1997) prescribed the object the enterprise is engaged in includes the competence such as the preservation or enhancement of enterprise innovation image, the addition of customer's added value, attraction of more new customers, awareness of customer's requirements, new services of response to competitors, more economized costs and massive customized-based services. Consequently, the outer contractor taking on the cases of operation of information systems outsourcing in financial services industry is supposed to assist the financial services industry to enhance the competence mentioned above.

\section{Research Procedure and Methodology}

\subsection{Research Procedure}

The main research procedures explained as below:

- Step 1: Defining the research theme, question description and research object

- Step 2: Gathering and compiling the literature reviews related to the operation of information system outsourcing decision mechanism issues and establishing the hierarchical structure

- Step 3: Outsourcing Theory is demarcated into 5 evaluation criteria and 17 sub-criteria by the Modified Delphi Approach

- Step 4: Expert questionnaire is developed by the hierarchical structure.

- Step 5: The weigh and rank of evaluation criteria and sub-criteria are acquired through analyzing by FAHP

- Step 6: Empirical analysis and conclusion

\subsection{Adopting Modified Delphi Approach to Establish Analytic Hierarchy Process}

The mode of Modified Delphi Approach was provided by Murry and Hommons (1995). The specific implementation and statistical approach of modified Delphi approach and traditional Delphi approach are in a similar way. Murry and Hommons (1995) ignored the complicated procedure on open-end questionnaire testing of first round, which is the dissimilarity with traditional Delphi approach. Either the related research result, the researcher's plan in literature 
reviews or the approach of expert interview enables to directly develop the structured questionnaire. Modified Delphi approach is able to economize the time consuming makes the experts concentrate on the research theme without the speculation to open-end questionnaire to arise the valid return rate.

Based on the related literature reviews and modified Delphi approach, the study establish the research theme and Analytic Hierarchy Process to separate the Outsourcing Theory of information systems into "the enterprise organization and management", "costs and financial factors", "system structure technology", "the enterprise ethic and laws", and "outsourcing contractor factors" as 5 criteria and 17 sub-criteria. The explanation of criteria and sub-criteria is stated as below.

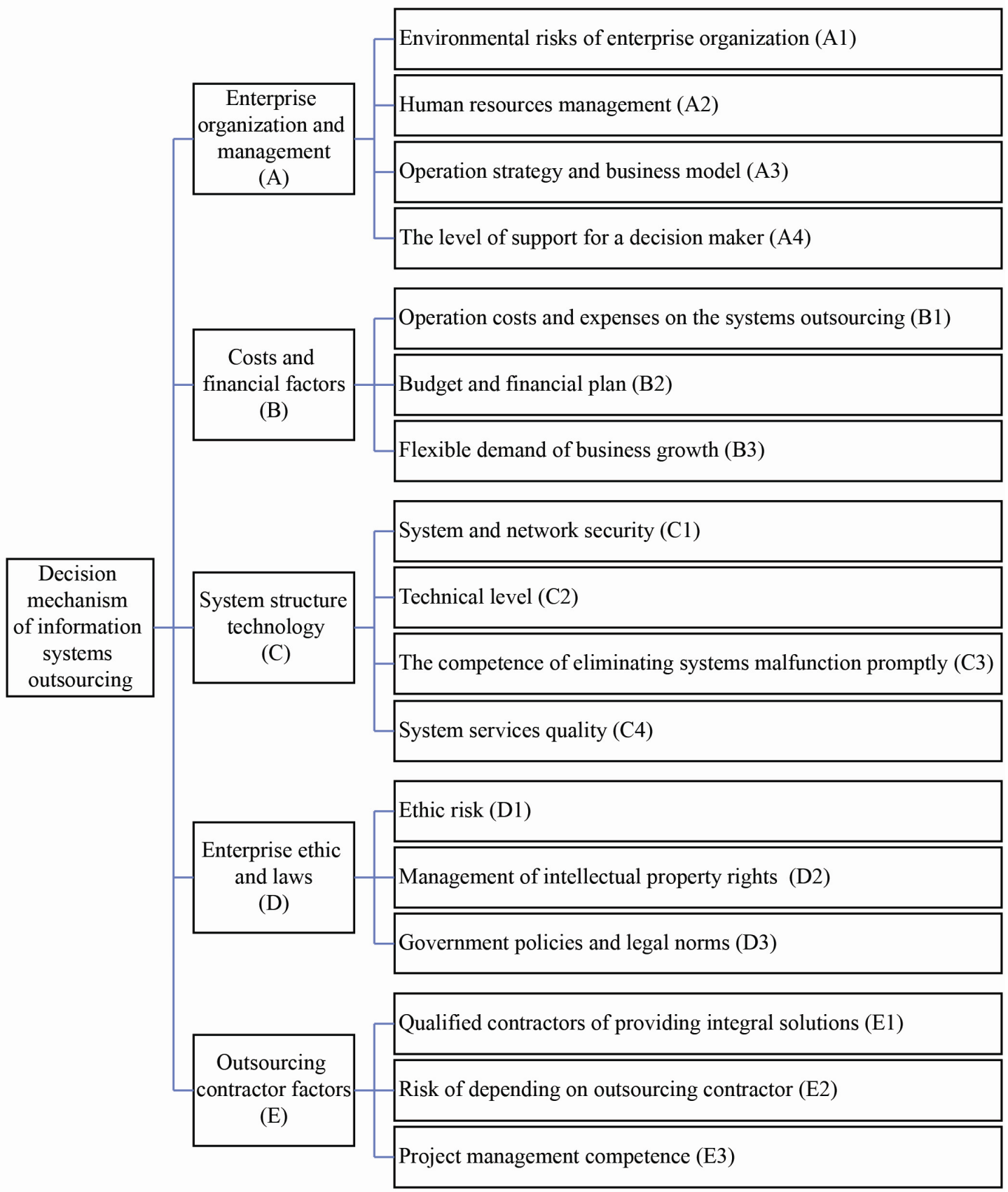

Figure 1. Hierarchical Structure of Problem in Application

Note. Source: Constructed by the authors in accordance with reviewing. 
Enterprise organization and management (A):

- Environmental risks of enterprise organization (A1): All potential influential factors or force may result in the influence on organization operating and performance. Environmental risks of organization decided the existence and development of organization. Environmental risks of organization result from the enterprise decisions, organization cultures, organization management, behavior of organization and coordination abnormality.

- Human resources management (A2): Human resources management refers to the series of human resources policies and reciprocal managerial activities. Human resources management includes a series of process such as employee recruitment, training, appointment, evaluation, motivation, adjustment and so on. The ultimate object of human resources is to facilitate the enterprise achievement.

- Operation strategy and business model (A3): The enterprise increases the existed and developed space while considering the enterprise-self advantage and disadvantage. Based on the prospect and operation object, the enterprise establishes the operation strategy and business model to carry out the enterprise value. New development of new science and technology and business model enhance not only the enterprise efficiency and benefits, but also the enterprise profitability either directly or indirectly.

- The level of support for a decision maker (A4): A decision maker's support influences on the establishment of enterprise regulation and strategy. The decision maker is able to be not only an individual, but the group. The organization would develop toward more positive direction in that the decision maker successfully provides the instructions and supports the employees need. In the process of facilitating significant plans, the level of support for a decision maker lowered inner obstacle and pressure.

Costs and financial factors (B):

- Operation costs and expenses on the systems outsourcing (B1): The enterprise benefit is able to be added as the enterprise curtailed the operation costs and expenses. The operation costs and expenses is as well as called enterprise overall cost, including the payable and all expenses of enterprise. For the sake of reducing the operation costs and expenses, the manager is frequently committed the partial business to outer organization.

- Budget and financial plan (B2): The budget and financial plan reflect the financial status and operating results during a period of time in the future. The enterprise effectively operates the resources and establishes the strategy of financial plan in order to benefit. Accordingly, budget and financial plan may well say to maximize the economic behavior under the legitimate premise.

- Flexible demand of business growth (B3): The enterprise has earned market competitive advantage by means of effective business mode and enterprise strategy in the process of growing business volume rapidly. The enterprise either introduced a new product and service or increased new channel; meanwhile, the information systems of enterprise is bound to accord with the demand of business growth. Not only does the enterprise need to establish new information systems or increase the load capacity of old system, but also take the outer resources into consideration to meet the needs.

System structure technology(C):

- System and network security (C1): Generally speaking, network security includes network hardware device security, network information protection and software security. Unsecure information systems and network may result in customer's sensitive personal data thieved or disclosed. In addition, the business competitor used cyber attack to damage the formal operation in the enterprise. Consequently, system and network security, the measure, adopted to take precautions against data thieved and business competitive attack.

- Technical level (C2): Technical level is a crucial sharp weapon for enterprise developing business management. The enterprise is bound to spend astronomical sums of funds on personnel training, software establishing and hardware purchasing in order to meet information science and technology of business. The competence of information management directly restricted the enterprise competence of providing customer service and product.

- The competence of eliminating systems malfunction promptly (C3): The systems terminated the operation through abnormal progress in the process of operating result in the information lost due to certain reasons. The situation is so-called "system malfunction". Systems malfunction may result from the software factors or hardware factors; as the result, the enterprise is bound to implement emergent contingency plan and precautious measures as well as protect the customer equity.

- System services quality (C4): The enterprise is bound to adopt advanced systems services quality to meet available and potential demands by taking the competitive advantage and effective resources allocation into consideration. 
Inner information department of enterprise would establish key performance indicators to evaluate the service quality by the time of providing services.

Enterprise ethic and Laws (D):

- Ethic risk (D1): The related issues derived from ethic risk are rather common in either economic or business activity. Ethic risk possesses the potentiality, permanency, destruction and the character beyond control; accordingly, not only is the client's benefit impaired, but also the reputation and goodwill permanently may be influenced should the enterprise violate business ethic and moral.

- Management of Intellectual Property Rights (IPR) (D2): Intellectual Property Rights (IPR) is one kind of incorporeal property right. The originator is engaged in creative activities to acquire the result, legally entitled to the right. Intellectual Property Rights (IPR), similar with tangible assets, possesses the character of economy entity, is as well as separated or shifted.

- Government policies and legal norms (D3): Government policies and legal norms refer to the government that regulates the standards and measures to contractors in order to realize the particular political and economic tasks. Trade, currency, environmental protection, government tax revenue and finance are involved in related with economic activities. As a result, precise policies and legislation are able to develop enormous catalyst effect on social economy.

Outsourcing contractor factors (E):

- Qualified contractors of providing integral solutions (E1): In response to the rapid variety of information science and technology development and business demands, the enterprise adapted the mode of outsourcing operation to acquire required information technology. How to search qualified and competence outsourcing contractors with integral solutions is the trouble that the enterprise is bound to encounter. Hence, under the limited situation of manpower and expense resources, the enterprise is supposed to establish different criteria to evaluate the competence of outsourcing contractors.

- Risk of depending on outsourcing contractor (E2): The risk for enterprise to outsourcing contractors resulted from over dependent on certain objects or matters. The enterprise is suppose to avoid to depend on outsourcing contractor excessively, which enables the enterprise lose the independent competence on controlling the business. The enterprise will encounter the issues such as communication problems, uncontrollable service quality, information security risk and so on.

- Project management competence (E3): Project management defines as the manager applies the knowledge, tool and technology of management to carry out the problems and demands occurred on project. Project management competence to enhance enterprise inner department is a crucial mode to subsist on the era of knowledge economy. Owning the potent project management competence enables the outer contractor to win the client's confidence to acquire the commitments or orders.

\subsection{Application of Fuzzy Analytic Hierarchy Process}

The operation of information systems outsourcing has not only been the trend in Asia Pacific Zone, but also the market demands increased in Taiwan. Accordingly, the financial services industry is bound to discover the perspective of information system outsourcing operation and related weighting evaluation criteria to consider whether the enterprises is committed to the information systems outsourcing. This study is aimed at the managers of information management departments to give out 17 expert questionnaires and received 15 effective questionnaires. The rate of return is $88.24 \%$. Sample period is between November 2013 and March 2014. The number of expert selections is based on Adler and Ziglio (1996) so that 10 to 15 homogeneous experts were required in the proceeding of questionnaire. Besides, Parenté and Anderson-Parenté (1987) and Couper (1984) described as well the number of experts remained 10 above at least who took part in continuously before the end of Delphi approach. This study grasped the questionnaire rate of return as well as possible now that it is a key point for a successful research whether the experts are able to participate in from stem to stern.

Analytic Hierarchy Process (AHP) was proposed by Thomas L. Saaty in 1971. It is used to gather the opinions from the scholars and experts, and systemize and stratify the complicated questions to deduct the risk of fault decision. In 1983, Van Laarhoven and Pedrycz stated Fuzzy Analytic Hierarchy Process (FAHP). The concept of fuzzy was adopted to solve the values in the pairwise comparison matrix with subjectivity, imprecision and vagueness...etc in traditional AHP. Therefore, FAHP is implemented in this study.

Following by the establishment of hierarchy architecture, each respondent respectively enables to give pairwise 
comparison matrices of the ultimate goal and criteria by a nine-point scale. The score of geometric mean from all survey respondents is made up as the middle value of Triangular Fuzzy Number (TFN) in this study. The largest value and the smallest value of score among all survey respondents are made up respectively as the upper bound and lower bound of TFN. Lambda-Max method which was reported by Csutora and Buckley (2001) is applied in this study to calculate fuzzy weights. The defuzzier is the subsequence. The value of $\mathrm{R}$ stands for the value in the wake of defuzzier. The larger the value of $\mathrm{R}$, the more precedential sequence the factor stands for.

According to the study method, fuzzy pairwise comparison matrix of each criterion in level 2 is complied as equation (1).

$$
\mathrm{T}_{2}=\left[\begin{array}{ccccc}
(1,1,1) & (0.33,0.79,4.00) & (0.25,1.54,5.00) & (0.25,1.51,6.00) & (0.50,2.85,7.00) \\
(0.25,1.27,3.00) & (1,1,1) & (0.33,1.58,6.00) & (0.25,1.85,4.00) & (0.50,2.97,7.00) \\
(0.20,0.65,4.00) & (0.17,0.63,3.00) & (1,1,1) & (0.20,0.97,6.00) & (0.33,1.94,6.00) \\
(0.17,0.66,4.00) & (0.25,0.54,4.00) & (0.17,1.03,5.00) & (1,1,1) & (0.25,1.51,5.00) \\
(0.14,0.35,2.00) & (0.14,0.34,2.00) & (0.17,0.52,3.00) & (0.20,0.66,4.00) & (1,1,1)
\end{array}\right]
$$

The fuzzy weights of each criterion in level 2 are showed as equation (2) to equation (6).

$$
\begin{aligned}
W_{A} & =\left[\begin{array}{lll}
0.1740 & 0.2591 & 0.3291
\end{array}\right] \\
W_{B} & =\left[\begin{array}{lll}
0.1708 & 0.3006 & 0.3006
\end{array}\right] \\
W_{C} & =\left[\begin{array}{lll}
0.1249 & 0.1767 & 0.2924
\end{array}\right] \\
W_{D} & =\left[\begin{array}{lll}
0.1215 & 0.1656 & 0.2846
\end{array}\right] \\
W_{E} & =\left[\begin{array}{lll}
0.0980 & 0.0980 & 0.1892
\end{array}\right]
\end{aligned}
$$

The fuzzy pairwise comparison matrices of sub-criteria under the enterprise organization and management factor, the cost and financial factor, the system structure technology factor, the enterprise ethic and law factor and the outsourcing contractor factor in level 2 are compiled respectively as equation (7) to equation (11).

$$
\begin{gathered}
\mathrm{T}_{31}=\left[\begin{array}{ccccc}
(1,1,1) & (0.25,0.64,5.00) & (0.20,0.41,4.00) & (0.17,0.53,3.00) \\
(0.20,1.57,4.00) & (1,1,1) & (0.17,0.59,2.00) & (0.20,0.77,6.00) \\
(0.25,2.44,5.00) & (0.50,1.69,6.00) & (1,1,1) & (0.33,1.28,5.00) \\
(0.33,1.89,6.00) & (0.17,1.29,5.00) & (0.20,0.78,3.00) & (1,1,1)
\end{array}\right] \\
\mathrm{T}_{32}=\left[\begin{array}{cccc}
(1,1,1) & (0.50,1.50,4.00) & (0.33,1.57,4.00) \\
(0.25,0.67,2.00) & (1,1,1) & (0.25,1.11,4.00) \\
(0.25,0.64,3.00) & (0.25,0.90,4.00) & (1,1,1)
\end{array}\right] \\
\mathrm{T}_{33}=\left[\begin{array}{ccccc}
(1,1,1) & (2.00,3.25,6.00) & (0.20,1.34,4.00) & (0.33,2.34,6.00) \\
(0.17,0.31,0.50) & (1,1,1) & (0.17,0.39,2.00) & (0.20,0.69,3.00) \\
(0.25,0.75,5.00) & (0.50,2.55,6.00) & (1,1,1) & (0.33,2.25,5.00) \\
(0.17,0.43,3.00) & (0.33,1.44,5.00) & (0.20,0.44,3.00) & (1,1,1)
\end{array}\right] \\
\mathrm{T}_{34}=\left[\begin{array}{cccc}
(1,1,1) & (0.20,0.99,5.00) & (0.17,1.15,6.00) \\
(0.20,1.01,5.00) & (1,1,1) & (0.17,0.88,5.00) \\
(0.17,0.87,6.00) & (0.20,1.14,6.00) & (1,1,1)
\end{array}\right] \\
\mathrm{T}_{35}=\left[\begin{array}{cccc}
(1,1,1) & (0.20,1.07,6.00) & (0.25,1.13,6.00) \\
(0.17,0.94,5.00) & (1,1,1) & (0.17,0.98,6.00) \\
(0.17,0.89,4.00) & (0.17,1.02,6.00) & (1,1,1)
\end{array}\right]
\end{gathered}
$$

Accordingly, the fuzzy weights of sub-criteria under the enterprise organization and management factor in level 2 are as equation (12) to equation (15).

$$
\begin{aligned}
& \mathrm{W}_{\mathrm{A} 1}=\left[\begin{array}{lll}
0.1445 & 0.1445 & 0.2886
\end{array}\right] \\
& \mathrm{W}_{\mathrm{A} 2}=\left[\begin{array}{lll}
0.1350 & 0.2179 & 0.2860
\end{array}\right] \\
& \mathrm{W}_{\mathrm{A} 3}=\left[\begin{array}{lll}
0.2179 & 0.3589 & 0.3589
\end{array}\right] \\
& \mathrm{W}_{\mathrm{A} 4}=\left[\begin{array}{lll}
0.1590 & 0.2787 & 0.3197
\end{array}\right]
\end{aligned}
$$


The fuzzy weights of sub-criteria under the cost and financial factor in level 2 are as equation (16) to equation (18).

$$
\begin{aligned}
& \mathrm{W}_{\mathrm{B} 1}=\left[\begin{array}{lll}
0.3781 & 0.4338 & 0.4338
\end{array}\right] \\
& \mathrm{W}_{\mathrm{B} 2}=\left[\begin{array}{lll}
0.2715 & 0.2947 & 0.3542
\end{array}\right] \\
& \mathrm{W}_{\mathrm{B} 3}=\left[\begin{array}{lll}
0.2715 & 0.2715 & 0.3940
\end{array}\right]
\end{aligned}
$$

The fuzzy weights of sub-criteria under the system structure technology factor in level 2 are as equation (19) to equation (22).

$$
\begin{aligned}
& \mathrm{W}_{\mathrm{C} 1}=\left[\begin{array}{lll}
0.3350 & 0.3976 & 0.3976
\end{array}\right] \\
& \mathrm{W}_{\mathrm{C} 2}=\left[\begin{array}{lll}
0.1198 & 0.1198 & 0.1706
\end{array}\right] \\
& \mathrm{W}_{\mathrm{C} 3}=\left[\begin{array}{lll}
0.1958 & 0.3213 & 0.4045
\end{array}\right] \\
& \mathrm{W}_{\mathrm{C} 4}=\left[\begin{array}{lll}
0.1390 & 0.1613 & 0.2941
\end{array}\right]
\end{aligned}
$$

The fuzzy weights of sub-criteria under the enterprise ethic and law factor in level 2 are as equation (23) to equation (25).

$$
\begin{aligned}
& \mathrm{W}_{\text {D1 }}=\left[\begin{array}{lll}
0.3197 & 0.3481 & 0.3481
\end{array}\right] \\
& \mathrm{W}_{\text {D2 }}=\left[\begin{array}{lll}
0.3197 & 0.3197 & 0.3251
\end{array}\right] \\
& \mathrm{W}_{\text {D3 }}=\left[\begin{array}{lll}
0.3197 & 0.3323 & 0.3672
\end{array}\right]
\end{aligned}
$$

The fuzzy weights of sub-criteria under the outsourcing contractor factor in level 2 are as equation (26) to equation (28).

$$
\begin{aligned}
& \mathrm{W}_{\mathrm{E} 1}=\left[\begin{array}{lll}
0.3543 & 0.3543 & 0.3648
\end{array}\right] \\
& \mathrm{W}_{\mathrm{E} 2}=\left[\begin{array}{lll}
0.2910 & 0.3240 & 0.3432
\end{array}\right] \\
& \mathrm{W}_{\mathrm{E} 3}=\left[\begin{array}{lll}
0.2910 & 0.3217 & 0.3217
\end{array}\right]
\end{aligned}
$$

\section{Empirical Results}

After that, the fuzzy weights of each criterion in level 2 multiplied by the fuzzy weights of each sub-criteria. The defuzzier values $(\mathrm{R})$ of each sub-criteria and final fuzzy weights are presented in Table 1.

Table 1. Final Fuzzy Weights and Defuzzier Values

\begin{tabular}{clrc}
\hline Rank & \multicolumn{1}{c}{ Sub-Criteria } & Final Fuzzy Weights & $\begin{array}{c}\text { Defuzzier (R) } \\
\text { Values }\end{array}$ \\
\hline 1 & $\begin{array}{l}\text { Operation costs and expenses on the systems outsourcing } \\
\text { (B1) }\end{array}$ & $(0.0646,0.1304,0.1304)$ & 0.1123 \\
2 & Operation strategy and business model(A3) & $(0.0379,0.0930,0.1181)$ & 0.0889 \\
3 & Flexible demand of business growth(B3) & $(0.0464,0.0816,0.1185)$ & 0.0868 \\
4 & Budget and financial plan(B2) & $(0.0464,0.0886,0.1065)$ & 0.0840 \\
5 & System and network security(C1) & $(0.0418,0.0702,0.1162)$ & 0.0815 \\
6 & The competence of eliminating systems malfunction & $(0.0244,0.0568,0.1183)$ & 0.0762 \\
& promptly(C3) & $(0.0277,0.0722,0.1052)$ & 0.0748 \\
7 & The level of support for a decision maker(A4) & $(0.0388,0.0550,0.1045)$ & 0.0713 \\
8 & Government policies and legal norms(D3) & $(0.0388,0.0576,0.0991)$ & 0.0695 \\
9 & Ethic risk(D1) & $(0.0388,0.0529,0.0925)$ & 0.0652 \\
10 & Management of intellectual property rights ( D2) & $(0.0235,0.0565,0.0941)$ & 0.0643 \\
11 & Human resources management(A2) & $(0.0251,0.0374,0.0950)$ & 0.0602 \\
12 & Environmental risks of enterprise organization(A1) & $(0.0174,0.0285,0.0856)$ & 0.0527 \\
13 & System services quality(C4) & $(0.0347,0.0347,0.0690)$ & 0.0488 \\
14 & Qualified contractors of providing integral solutions(E1) & $(0.0285,0.0318,0.0649)$ & 0.0447 \\
15 & Risk of depending on outsourcing contractor(E2) & $(0.0285,0.0315,0.0609)$ & 0.0427 \\
16 & Project management competence(E3) & $(0.0150,0.0212,0.0499)$ & 0.0323 \\
17 & Technical level (C2) & & \\
\hline
\end{tabular}

Note. Source: Constructed by the authors in accordance with reviewing. 
All interviewed experts made use of pairwise comparison method to fill out the questionnaire. Furthermore, the questionnaires were compiled by advance integration to proceed analysis by FAHP programmed from the software named Matlab.

The result of research appeared the top 5 key factors influencing the decision mechanism of information systems outsourcing operation in financial services industry in Taiwan are "operation costs and expenses on the systems outsourcing" ( $\mathrm{R}=0.1123)$, "operation strategy and business model" $(\mathrm{R}=0.0889)$, "flexible demand of business growth" $(\mathrm{R}=0.0868)$, "budget and financial plan" $(\mathrm{R}=0.0840)$, "system and network security" $(\mathrm{R}=0.0815)$ respectively. The other factors of the operation of information systems outsourcing in financial industry caused less influence on "technical difficulty" ( $\mathrm{R}=0.0323)$, "project management competence" $(\mathrm{R}=0.0427)$, "risk of depending on outsourcing contractor" $(\mathrm{R}=0.0447)$, "qualified contractors of providing integral solutions" $(\mathrm{R}=0.0488)$ and "systems services quality" $(\mathrm{R}=0.0527)$.

Among all influential factors, "operation costs and expenses on the systems outsourcing" is the first priority while adapting the information systems outsourcing in financial services industry. As far as the enterprise concerned, adapting cost control is as the crucial measure to pursue the optimum benefit to carry out the object. Hence, lowering the cost is the basis propellent factor of operation of information systems outsourcing. With the globalization of enterprise resources allocation increasingly, the financial services industry is committed to information systems outsourcing operation, which is able to reduce the operating cost to acquire higher benefits. According to Mortimer et al. (1993), the main reason that the enterprise considered adapting operation of information systems outsourcing is so as to reduce the cost. Additionally, specialized outsourcing services of outer contractors enable the enterprise cost to be more predictable and controllable.

The secondary crucial element is "operation strategy and business model", which stands for the further enhancement of enterprise to the specialized division consciousness. Practical specialized division contributes more resources to enhancement of enterprise core competition. Lacity et al. (1995) stated the enterprise is supposed to take notice of long-term investment in fundamental business to improve the participation and control for the business units to the software, which enables the enterprise to plunge more time and resources into the major tasks of organization. The enterprise is supposed to enhance the management competence of information system and enable the inner resources to be used effectively as the changes of users' demands and uncertain investment of research and development. As a result, the financial institution chooses the operation of information systems outsourcing, a new option of operating strategy and mode. Adapting successful operation of information system outsourcing not only facilitates the various resources in the enterprise re-allocated by financial institution, but also concentrates the energy on core business to establish and strengthen the enterprise-self core competence.

The third crucial factor is "flexible demand of business growth". The mode of current procedure in financial services industry is difficult to meet the demands for rapid business development. The result reconciles with the concept the information systems is bound to upgrade while the business growth rising provided by Clemons and Weber (1990). Over-stressful workload of employee, excessive operating cost and limited efficient enhancement disable the financial institution to possess the adequate economic scale. Accordingly, the adoption of operation of information systems outsourcing enables to facilitate the financial services industry to meet the variation of market demands constantly and formulate the competitive advantage of flexible operating.

"Budget and financial plan" is as the fourth factor of the result, which appears the financial budget establishment and predictable future growth and funds demand are bound to be valued by financial services industry aside from reducing the operating cost and expenses. Providing the outsourcing contractor strengthens the control and management of inner cost and provides high quality service with low cost, it will more easily acquire the favor in financial services industry within maintaining the service quality. Lacity and Hirschheim (1995) advised the enterprise is suppose to plan the annual financial budget and scheme to carry out the annual operation objectives assuredly.

Both "system and network security" and "promptness of systems malfunction elimination" are the fifth and sixth crucial factors to influence the operation of information systems outsourcing in financial services industry respectively. Following by the rapid development of network, the security operation of business system of financial institution encounters a significant trail. The vulnerability detection of business system and the emergency procedure of safety are tackled by the specialized contractors to assure the business system in operating safely. Also, the efficiency of operating information systems increases sharply.

In addition, it is noteworthy that "government policies and legal norms" $(\mathrm{R}=0.0713)$, "ethic risk" $(\mathrm{R}=0.0695)$ and "Intellectual Property Rights (IPR)" ( $\mathrm{R}=0.065)$, the factors related to ethic and legislation of enterprise, ignored by 
the financial institute among seventeen factors. The government disregarded the current development of information systems outsourcing, nor established the responsive policies and supportive legislation, which may be the major reason. The industry of information systems outsourcing is in its infancy at the moment; therefore, the manager of enterprise for the recognition does not reach a certain level. Industry ethic and managerial mode do not possess complete mechanism. Moreover, the empirical result discovered the less influences on "human resources management" $(\mathrm{R}=0.0643)$ and "environmental risks of enterprise organization" $(\mathrm{R}=0.0602)$, which differentiates from Brown et al. (1998) and Wallace et al. (2004).

Besides, "qualified contractors of providing integral solutions" $(\mathrm{R}=0.0488)$, "risk of depending on outsourcing contractor" $(\mathrm{R}=0.0447)$ and "project management competence" $(\mathrm{R}=0.0427)$ are less crucial influential factors relatively. Generally speaking, the operation of information systems outsourcing enables the financial institute to depend on outer contractor to a certain extent, which exists some potential risk. Next, outer contractor disables to provide satisfactory service to enterprise as the information systems need to be improved or upgraded. With the increasing dependence for the financial institute to outer contractor, the learning competence of organization weakens gradually as well. Finally, the "technical level" is the least crucial influential factor. The aim of information systems outsourcing operation is at acquiring competence with high-tech of information following by the development and application of new technology. Hence, the financial institution does not care about the technical problem of structure information systems, the major reason of which lies on the related technology mastered fully in the industry. In other words, the issue of technical level will not make too much impact on decision mechanism of financial institution. Regarding the operation of information systems outsourcing as long-term strategic management tool is more supposed to be valued by enterprise in the era emphasizing on enterprise core competition.

\section{Conclusion}

As a response to the global market with increasing competition, more and more enterprises are committed the information systems to specialized outer contractors to structure and manage. The operation of information systems outsourcing is expected to reduce the annual expense of enterprise and provide flexible information resources, which correspondences with the current and potential enterprise business demands. The operation of information systems outsourcing is regarded as the indicator whether possesses sustainable operation competition for an enterprise. Take the financial services industry in Taiwan as an example, exploring the decision mechanism and influential factors as the financial institution establishing operating decision of information systems outsourcing is the issued concerned severely in the industry. Related literature reviews with modified Delphi approach are complied to establish the structure of Analytic Hierarchy Process on the study. Fuzzy Analytic Hierarchy Process was adopted as the methodology to clarify the decision mechanism of committed operation of information systems outsourcing in services industry in Taiwan. The empirical result is able to support the insufficient former related literatures and be proposed for the reference of decision of operation of information systems outsourcing established by financial services industry in Taiwan.

The empirical result appeared "operation costs and expenses on the systems outsourcing" is the crucial factor the decision valued the most by financial services industry in Taiwan. High expenses on information systems structure, maintenance and management are able to be economized for the financial institution by operation of information systems outsourcing, which enables the financial institution to allocate more resources into core business. Next, "operation strategy and business model", "flexible demand of business growth", "budget and financial plan" and "system and network security" are the crucial factors considered by financial institution. Relatively, "government policies and legal norms", "ethic risk" and "Intellectual Property Rights (IPR)" are not taken into consideration as the financial institution established the decision.

To sup up, the financial institution is supposed to strengthen itself core competence to constantly comply with the variation of market development, as well as concentrate more resources on developing core business. The mode of operating information systems outsourcing not only enhances the competitive advantage in financial services industry in Taiwan, but also influences the operating strategy and market distribution. In meanwhile, the enterprise is supposed to evaluation various factors from inner and outer organizations to establish the evaluated mechanism qualified for real situation whether adopting the operation of information system outsourcing. The financial institution needs to make use of effective supervision and control on outsourcing contractor as taking various factors of risk management into consideration. The financial institution will make the most adequate decision and determine the operating level and ratio of information systems outsourcing by means of establishing evaluated mechanism of outsourcing contractor. The information systems business contractor is bound to possess expertise, human resources, specialized management competence and service quality as well to be staunch backing of financial institution. In the 
era of emphasizing the enterprise core competition, the financial services industry in Taiwan is supposed to more regard the operating mode of information system outsourcing as the crucial strategy of sustainable operation ideal.

\section{References}

Adler, M., \& Ziglio, E. (1996). Gazing into the oracle: The Delphi method and its application to social policy and public health. Jessica Kingsley Publishers.

Antonucci, Y. L., \& Tucker III, J. J. (1998). IT outsourcing: Current trends, benefits, and risks. Information Strategy: The Executive's Journal, 14(2), 16-26.

Bhattacharyaa, S., Beharab, R., \& Gundersenc, D. (2003). Business risk perspectives on information systems outsourcing. International Journal of Accounting Information Systems, 4, 75-93. http://dx.doi.org/10.1016/S1467-0895(03)00004-6

Bourantas, D. (1989). Avoiding dependence on suppliers and distributors. Long Range Planning, 22(3), 140-149. http://dx.doi.org/10.1016/0024-6301(89)90016-2

Brown, W. J., Malveau, R. C., Brown, W. H., McCormick, H. W. III, \& Mowbray, T. J. (1998). .Anti patterns: Refactoring software, architectures, and projects in crisis. NY: John Wiley and Sons.

Chang, S. C., \& Lee, M. S. (2007). The effects of organizational culture and knowledge management mechanisms on organizational innovation: An empirical study in Taiwan. The Business Review, 7(1), 295-301.

Claver, E., González, R., Gascó, J., \& Llopis, J. (2002). Information systems outsourcing: Reasons, reservations and success factors. Logistics Information Management, $15(4), \quad 294-308$. http://dx.doi.org/10.1108/09576050210436138

Clemons, E. K., \& Weber, B. W. (1990). Strategic information technology investments: Guidelines for decision making. Journal of Management Information Systems, 9-28.

Couper, M. R. (1984). The Delphi technique: Characteristics and sequence model. Advances in Nursing Science, 7(1), 72-77. http://dx.doi.org/10.1097/00012272-198410000-00008

Csutora, R., \& Buckley, J. J. (2001). Fuzzy hierarchical analysis: The Lambda-max method. Fuzzy Sets and Systems, 120, 181-195. http://dx.doi.org/10.1016/S0165-0114(99)00155-4

Damanpour, F., \& Evan, W. M. (1984). Organizational innovation and performance: The problem of organizational lag. Administrative Science Quarterly, 392-409. http://dx.doi.org/10.2307/2393031

Daniel, E., \& Storey, C. (1997). On-line banking: Strategic and management challenges. Long Range Planning, 30(6), 890-898. http://dx.doi.org/10.1016/S0024-6301(97)00074-5

Directorate General of Budget, Accounting and Statistics, Executive Yuan, Taiwan. (2011). Computer use survey. Taipei, R.O.C.: Directorate General of Budget, Accounting and Statistics, Executive Yuan, Taiwan.

Due, R. T. (1992). The real costs of outsourcing. Information Systems Management, 9(1), 78-81. http://dx.doi.org/10.1080/10580539208906854

Goldsmith, R. F. (1994). Confidently outsourcing software development. Journal of Systems Management, 45, 12-12.

Gordon, K. A. (1994). Outsourcing information technology. Fortnightly (United States), 132(2).

Grover, V., Cheon, M. J., \& Teng, J. T. (1996). The effect of service quality and partnership on the outsourcing of information systems functions. Journal of Management Information Systems, 89-116.

Hsu, C., Wu, C., \& Hsu, J. C. (2005). Performance evaluation of information system outsourcing in Taiwan's large enterprises. Journal of American Academy of Business, 6(1), 255-259.

Hubbard, G. M. (1993). Making tough outsourcing decisions work for you. Facilities Design and Management, 12, 46-46.

Jennex, M. E., \& Adelakun, O. (2003). Success factors for offshore information system development. Journal of Information Technology Case and Application Research, 5(3), 12-31. http://dx.doi.org/10.1080/15228053.2003.10856024

Kimberly, J. R., \& Evanisko, M. J. (1981). Organizational innovation: The influence of individual, organizational, and contextual factors on hospital adoption of technological and administrative innovations. Academy of Management Journal, 24(4), 689-713. http://dx.doi.org/10.2307/256170 
Klepper, R., \& Jones, W. O. (1999). Outsourcing information technology, systems, and services.

Laabs, J. J. (1993). Successful outsourcing depends on critical factors. Personnel Journal.

Lacity, M., \& Hirschheim, R. (1995). Beyond the information systems outsourcing bandwagon: The insourcing response. Chichester, NY: Wiley.

Lacity, M., Willcocks, L., \& Feeny, D. (1995). Information technology outsourcing: Maximizing flexibility and control. Harvard Business Review, 73(3), 84-93.

Lee, J. N., \& Kim, Y. G. (1999). Effect of partnership quality on IS outsourcing success: Conceptual framework and empirical validation. Journal of Management Information Systems, 29-61. http://dx.doi.org/10.2307/249407

Lee, J. N., Huynh, M. Q., Kwok, R. C. W., \& Pi, S. M. (2003). IT outsourcing evolution: Past, present, and future. Communications of the ACM, 46(5), 84-89. http://dx.doi.org/10.1145/769800.769807

Lloréns Montes, F. J., Ruiz Moreno, A., \& García Morales, V. (2005). Influence of support leadership and teamwork cohesion on organizational learning, innovation and performance: An empirical examination. Technovation, 25(10), 1159-1172. http://dx.doi.org/10.1016/j.technovation.2004.05.002

Loh, L. (1994). An organizational-economic blueprint for information technology outsourcing: Concepts and evidence. ICIS 1994 Proceedings, 7.

Loh, L., \& Venkatraman, N. (1992). Determinants of information technology outsourcing: A cross-sectional analysis. Journal of Management Information Systems, 7-24.

Meyer, N. D. (1994). A sensible approach to outsourcing: The economic fundamentals. Information Systems Management, 11(4), 23-27. http://dx.doi.org/10.1080/07399019408964666

Mortimer, T., Waterhouse, P., \& Court, C. (1993). Outsourcing: Getting it right. Datapro Computer System Hardware and Software, Nov., 10-15.

Murry, J. W., \& Hammons, J. O. (1995). Delphi: A versatile methodology for conducting qualitative research. Review of Higher Education, 18(4), 423-436.

Nam, K., Rajagopalan, S., Rao, H. R., \& Chaudhury, A. (1996). A two-level investigation of information systems outsourcing. Communications of the ACM, 39(7), 36-44. http://dx.doi.org/10.1145/233977.233989

Palvia, P. C. (1995). A dialectic view of information systems outsourcing: Pros and cons. Information and Management, 29(5), 265-275. http://dx.doi.org/10.1016/0378-7206(95)00030-9

Parenté, F. J., \& Anderson-Parenté, J. K. (1987). Delphi inquiry systems. Judgmental Forecasting, 129-156.

Robbins, S. P., \& Judge, T. A. (2006). Comportements organisationnels. P. Gabilliet (Ed.). Pearson Education.

Saunders, C., Gebelt, M., \& Hu, Q. (1997). Achieving success in information systems outsourcing. California Management Review, 39(2), 63-79. http://dx.doi.org/10.2307/41165887

Takac, P. F. (1994). Outsourcing: A key to controlling escalating IT costs? International Journal of Technology Management, 9(2), 139-155.

Tarricone, P. (1997). Outsourcing turns to smart sourcing. Facilities Design and Management, 16(2), 40-43.

Van Laarhoven, P. J. M., \& Pedrycz, W. (1983). A fuzzy extension of Saaty's priority theory. Fuzzy Sets and Systems, 11, 229-241. http://dx.doi.org/10.1016/S0165-0114(83)80082-7

Wallace, L., Keil, M., \& Rai, A. (2004). How software project risk affects project performance: An investigation of the dimensions of risk and an exploratory model. Decision Sciences, 35(2), 289-321. http://dx.doi.org/10.1111/j.00117315.2004.02059.x

Willcocks, L., Lacity, M., \& Fitzgerald, G. (1995). Information technology outsourcing in Europe and the USA: Assessment issues. International Journal of Information Management, 15(5), 333-351. http://dx.doi.org/10.1016/0268-4012(95)00035-6 